\section{Dóra Chor'}

Márcia Guimarães de Mello Alves"

Luana Giatti"'

Nágela Valadão Cade ${ }^{\mathrm{IV}}$

Maria Angélica Nunes ${ }^{\vee}$

Maria del Carmen Bisi Molina ${ }^{\mathrm{VI}}$

Isabela M Benseñor ${ }^{\mathrm{VII}}$

Estela M L Aquino ${ }^{\text {VIII }}$

Valéria Passos"II

Simone M Santos ${ }^{1}$

Maria de Jesus Mendes da Fonsecal

\section{Letícia Cardoso de Oliveira'}

Departamento de Epidemiologia e Métodos Quantitativos. Escola Nacional de Saúde Pública. Fundação Oswaldo Cruz. Rio de Janeiro, RJ, Brasil

" Departamento de Planejamento em Saúde. Instituto de Saúde da Comunidade. Universidade Federal Fluminense. Rio de Janeiro, RJ, Brasil

III Departamento de Nutrição Clínica e Social Escola de Nutrição. Universidade Federal de Ouro Preto. Ouro Preto, MG, Brasil

Iv Departamento de Enfermagem. Programa de Pós-Graduação em Saúde Coletiva. Universidade Federal do Espírito Santo. Vitória, ES, Brasil

$\checkmark$ Programa de Pós-Graduação em Epidemiologia. Faculdade de Medicina. Universidade Federal do Rio Grande do Sul. Porto Alegre, RS, Brasil

v1 Departamento de Educação Integrada em Saúde. Programa de Pós-Graduação em Saúde Coletiva. Universidade Federal do Espírito Santo. Vitória, ES, Brasil

VII Centro de Pesquisa Clínica e Epidemiológica. Hospital Universitário. Universidade de São Paulo. São Paulo, SP, Brasil

VIII MUSA Programa Integrado em Gênero e Saúde. Instituto de Saúde Coletiva. Universidade Federal da Bahia. Salvador, BA, Brasil

Correspondence:

Dóra Chor

Escola Nacional de Saúde Pública Fundação Oswaldo Cruz

R. Leopoldo Bulhões, 1480 Manguinhos

21041-210 Rio de Janeiro, RJ, Brasil

E-mail: dorachor@fiocruz.br

\section{Questionnaire development in ELSA-Brasil: challenges of a multidimensional instrument}

\section{ABSTRACT}

This article describes the development of the Brazilian Longitudinal Study for Adult Health (ELSA-Brasil) questionnaire. We first address the selection of topics whose contents have to cover the knowledge available on the complex causal network of outcomes and allow comparability with similar studies. Then we deal with the "translation and adaptation of measurement instruments" including neighborhood environment rating scales, depression and anxiety disorder rating scale and a food frequency questionnaire and discuss criteria that guided "theme block sequencing". And finally we focus on the practical importance of "pretesting and pilot studies". The ELSA may provide an original contribution regarding factors that cause or aggravate the outcomes of interest in the Brazilian population, as well as protective factors.

DESCRIPTORS: Questionnaires. Data Collection. Socioeconomic Factors. Life Style. Food Habits. Risk Factors. Multicenter Studies as Topic, methods. Cohort Studies. 


\section{INTRODUCTION}

Good quality questionnaires are prerequisite to validity of study results. ${ }^{5}$ Information from general objective questions (e.g., smoke/do not smoke) or questions on abstract concepts (e.g., job stress), collected using rating scales, can only be captured using a questionnaire as compared with assessments or measurements. A questionnaire can provide information on, for example, psychosocial aspects of childhood and adolescence or the respondent's perceived health. Understanding causal mechanisms of health outcomes as complex and comprehensive and determinants that are not closely related to the outcome of interest (e.g., parental education) have gained momentum in the investigation of chronic diseases.

The questionnaire is a key component of the Brazilian Longitudinal Study for Adult Health (ELSA-Brasil). The relationships of its contents and results of assessments and measurements can substantially contribute to understanding factors that may cause, aggravate or protect against cardiovascular diseases and type 2 diabetes in the Brazilian context. Potential variability of results between the six ELSA investigation centers in different Brazilian regions may improve the original contribution of the study. Bearing in mind distinctive characteristics of the Brazilian scenario, we opted to focus on social determinants of health. Capturing the potential impact of some factors (e.g., socioeconomic status), social and racial inequalities and health-related living conditions on outcomes of interest over the course of life may make the difference between what is already known and what the ELSA findings can add to scientific knowledge. ${ }^{1}$

In the following sections we describe the work of the ELSA Exposures Committee (EEC) advising and collaborating with the ELSA Research Steering Committee (ERSC) in developing the questionnaire. The development of questionnaires for different study designs has common steps such as selection of topics and pilot testing. But a longitudinal design requires a different approach from baseline. Interview duration is a common concern in all designs, but it is particularly important when subject participation and retention over many years are vital to validity of results. In the ELSA, some topics were considered less relevant and were left out to be included in the second round of data collection (wave 2) from 2012. The content of the questionnaire for wave 2 was determined based on criteria for covering the same topics included in the questionnaire for wave 1: significant changes in frequency and intensity of exposure (e.g., $30 \%$ of subjects moved after wave 1 of the study with an impact on the assessment of living conditions) and required exposure status update. In other circumstances, a topic was reassessed with a different instrument (e.g., job stress). All these issues have to be examined to determine the inclusion of new topics that were not investigated in wave 1 . Therefore, there should be a balance between concerns of subject retention, affected by the length of wave 2 , and investigation of all relevant exposures.

\section{DATA COLLECTION STRATEGY}

One of the first decisions of the ERSC was to conduct data collection through interviews and a self-administered questionnaire. Both approaches have been applied in a preliminary study with a sample of 144 subjects (24 in each ELSA study site). Comparisons were made between answers to key questions (e.g., smoking and income), surveys with participants were conducted, and interviewers' comments were examined. Based on these findings, we opted to use in the study face-to-face interviews.

\section{SELECTION OF TOPICS}

Selection of topics is usually a major challenge in questionnaire development. Many times some questions included in questionnaires are never analyzed, wasting time, and human (e.g., interviewer training, interview work) and financial resources.

For selecting topics to be investigated we took into consideration the knowledge available on the events of interest, comparability with similar studies, the complex network of causal study outcomes and interview duration. Information from a wide variety of sources was assessed to ensure that interrelationships between different dimensions associated to these outcomes, mediating factors, effect modifiers, and potential confounders would be investigated.

The work involved face-to-face workshops, EEC teleconferences, consultations with experts, and reference to questionnaires and manuals of major international epidemiological. ${ }^{4,8,22}$

After selecting a number of topics and instruments (Table 1) the ERSC developed a "Quality Control Form" (Table 2) to systematize information regarding each potential subject to be included in the ELSA questionnaire for assisting them with decision making. This information consisted of rationale, main characteristics, quality of measuring instruments, and key references on the topic. These forms listed all topics assessed - either they were included or not in the study questionnaire and were key to the questionnaire development. This inventory is a valuable lesson learned to be shared with other researchers.

Some topics were included by consensus of the EEC and ERSC as they were classic subjects of the epidemiology of cardiovascular diseases and diabetes (e.g., 
Table 1. Topics included in the Longitudinal Study for Adult Health questionnaire.

\begin{tabular}{ll}
\hline Sociodemographic & Age, gender, skin color/race/ethnicity \\
characteristics, $\mathrm{b}$ & Migration history, place of residence, length of living in this area \\
& Educational and occupational history (respondent and spouse) \\
& Family income and asset ownership \\
& Housing conditions and household composition (current and past) \\
& Family life and spouse/partner characteristics \\
& Head of household \\
& Religion (current and past) \\
& Parental education and occupation \\
& Living conditions during childhood
\end{tabular}

Past medical history ${ }^{a}$ Self-rated health, past medical history of cardiovascular diseases, diabetes, kidney disease, cancer and other chronic diseases; medical procedures of interest Angina ${ }^{5}$, intermittent claudication and heart failure questionnaire Headache questionnaire

$\begin{aligned} & \text { Occupational } \\ & \text { history }^{\mathrm{a}, \mathrm{b}}\end{aligned}$
Family history
$\begin{aligned} & \text { Reproductive } \\ & \text { history }^{\mathrm{b}}\end{aligned}$

Access to health care $^{b}$

Psychosocial factors $^{\mathrm{a}, \mathrm{b}}$

History of body weight and image ${ }^{b}$

Food consumption ${ }^{\mathrm{b}}$

Smokinga

Alcohol consumption $^{\mathrm{b}}$

Physical activity ${ }^{b}$

Medication use ${ }^{b}$

Cognitive function ${ }^{\mathrm{b}}$ for Alzheimer's disease validated for the Brazilian population.

Trail test to assess executive cognitive function related to attention, concentration and psychomotor speed.

Verbal fluency tests: animals and words beginning with the letter $\mathrm{F}$

Mental health ${ }^{b}$

Job stress

Job characteristics (level of autonomy, budget management, authority)

Retirement

Family-work imbalance

Family history of specific conditions such as cardiovascular diseases, diabetes and sudden death

Menarche, menstrual cycles and menopause

Contraceptive use

Reproductive history

Hormone therapy

Infertility

Access to screening programs, health insurance and utilization of health services

Environment/neighborhood characteristics (leisure, sports, food shopping)

Social network

Experience of discrimination

Social capital

Vital events

Self-assessment of social status

Birth weight and weight at age 20

Body image (current and desired)

Food frequency questionnaire

Former and current smoking, lifetime tobacco use, attempts to quit smoking with drug therapy, use of tobacco products with lower nicotine content, passive smoking

Type of alcoholic beverages; alcohol use frequency; pattern of alcohol consumption

Current physical activity including occupational, home, leisure-time activities and sports

Use of prescription and non-prescription medication, vitamins, dietary supplements, and other drugs used in the past month

Patients were asked to bring to the study visit all medications and prescription drugs they are on

Clinical Interview Schedule-Revised 16 validated for Brazilian Portuguese including all 14 sections: somatic symptoms, fatigue, concentration, depression, irritability, sleep, concerns with physical symptoms, depressive thoughts, worry, anxiety, phobia, panic, compulsions and obsessions

\footnotetext{
a Stage 1: Workplace interview

b Stage 2: Interview + assessments at ELSA study site
} 
Table 2. Quality control form on the topic job stress.

Description / Rationale

The purpose of the inclusion job stress scale(s) in the ELSA questionnaire is to explore the associations of this construct with main study outcomes (cardiovascular diseases and diabetes). There are virtually no studies on job stress conducted in Brazil. Two scales have been used in other countries to assess job stress. The oldest one, proposed by Robert Karasek in the 1970s, is based on the demand-control model. In 1982, Johannes Siegrist proposed a new instrument based on two other concepts: effort and reward. The dimensions evaluated in each scale are different, but both were used in the Whitehall Study (Levi et al, 2000).

Cross-cultural adaptations for both scales are available in Brazil, and it was suggested to include both at baseline. There is evidence showing that both scales should be concomitantly administered because they assess different dimensions of job stress and may help better understanding potential associations with health outcomes (Kivimaki et al, 2006; Chandola et al, 2005; Calnan et al, 2004; Ostry et al, 2003; Kivimaki et al, 2002, Peter et al, 2002) and cardiovascular events.

Association between job stress and ELSA outcomes

A recent meta-analysis on the association between job stress and coronary heart disease showed considerable heterogeneity of effects across studies, and a scarcity of studies with an adequate sample of women. This metaanalysis included both measurement scales and found a 50\% higher risk of coronary heart disease among workers classified as having job stress (Kivimaki et al, 2006).

Similarly, there were no consistent results regarding the association with hypertension. The results of most studies suggest a positive association with systolic and/or diastolic blood pressure among men but not among women. (Ohlin et al 2007; Belkic et al, 2000 and Brisson, 2000).

It is interesting to note different results for diabetes according to the scale applied: no association was found using the demand-control scale (Agardh et al, 2003; Kroenke, 2006); the Whitehall II Study applied the effort-reward scale and reported a positive association (Kumari et al, 2004). However, the number of studies using these scales, either together or individually, was low for this outcome. As for metabolic syndrome, a positive association was reported in the Whitehall Study (Chandola, 2006) using the demand-control scale.

Instrument characteristics

The demand-control scale consists of 17 questions with four answer choices that assess three dimensions: psychological demands (5 questions), control of work process (6 questions), and social support at work (6 issues). The first two dimensions are scored on a 1-4 Likert scale ("often" to "hardly ever or never"); the social support scale is scored on a scale indicating extent of agreement/disagreement ("strongly agree" to "strongly disagree"). Each dimension generates a score that allows to assessing exposure as a continuous ordinal (demand-control ratio) or categorical variable (obtained by combining the demand and control dimensions).

The effort-reward scale consists of 23 questions with four answer choices that assess three dimensions: effort (extrinsic, 6 questions), reward (11 questions), and overcommitment (intrinsic effort, 6 questions). The dimensions are scored on a 1-5 Likert scale indicating the extent of agreement/disagreement and intensity of discomfort. Each dimension generates a score that allows to assessing exposure as a continuous ordinal (effort-reward ratio) or categorical variable (ratio is divided into tertiles).

Validity/Accuracy and Reliability

In a Brazilian cohort study of workers (Pró-Saúde Study) (Alves et al, 2004) the internal consistency of the instrument was estimated at $0.72,0.63$ and 0.86 (Cronbach's alpha coefficient)for demand, control, and social support dimensions, respectively. The agreement estimated by intraclass correlation coefficient was $0.88,0.87$ and 0.86 for the same dimensions, respectively. A preliminary assessment of the scale factor structure and its three dimensions — demand, control and social support- was consistent with the theoretical model.

For effort-reward scale reliability (intraclass correlation coefficient) of its three dimensions (effort, reward and overcommitment) was $0.76,0.86$, and 0.78 , respectively. Estimates of internal consistency (Cronbach's alpha) for these same dimensions were $0.68,0.78$, and 0.78 , respectively. The factor structure was fairly consistent with the theoretical model.

family history of disease, previous medical diagnoses). Other more recent topics (e.g., job stress) were included because of the type of cohort population (workers) as well as evidence showing its association with the outcomes of interest. General topics such as self-rated health, reproductive health and access to health services, more general, were also consensually included.

The decision to give priority to social determinants of health among exposures investigated in the ELSA was also consensual. Not only because of the Brazilian background, but because they are novel exposures less investigated in other cohort studies. In addition to the classic variables associated to socioeconomic conditions - education and income - other relevant aspects of childhood (e.g., parental education and occupation) were included, which gives a life course approach to the study of chronic disease epidemiology. Location information (e.g., city, neighborhood) were collected at key time points (e.g., birth, early school life) to complement information on current area of residence for georeferencing. In addition to social capital measures ${ }^{23}$ and social 
class categorization, ${ }^{10}$ questions on health-related environment characteristics (neighborhood variables) ${ }^{18}$ are included in a questionnaire for the first time in Brazil. ${ }^{19}$

The inclusion of instruments for assessment of cognitive function is exceptional. Despite its relevance, the assessment of cognitive function requires the administration of memory (learning and word retention), language (verbal fluency tests), and executive function tests (trail-making test) that are relatively complex and time-consuming, a reason to hesitate to include them in wave 1 . But we pondered that it might allow to examine cognitive function cross-sectionally and longitudinally in different birth cohorts especially in those over 35 years of age, which is uncommon in similar studies, and to investigate its relationship with cardiovascular diseases and diabetes. Following intense debate, the assessment of cognitive function was included in the ELSA. ${ }^{3}$

Regarding other topics, the discussion was about what approach to take and instrument to use. For instance, as for food intake, it was defined that our main goal was to assess food consumption patterns. Also, we were aware there were no ideal gold standards to determine the validity of instruments of food intake data collection. We opted for the food frequency questionnaire (FFQ) because it provides information on regular dietary intake (food and nutrients) and allows classification of individuals into intake categories and has been widely used in studies similar to the ELSA. The FFQ, that was validated by Sichieri \& Everhart (1998), ${ }^{20}$ was used compared to the 24-hour recall. It was found Pearson coefficients of correlation ranging between 0.55 and 0.18 for calcium and vitamin A, respectively. ${ }^{20}$ In the ELSA-Brasil validity study, the modified FFQ was compared to three food records. Most coefficients of intraclass correlation were higher than 0.35 , and ranged between 0.72 and 0.20 for calcium and selenium (unpublished results).

The inclusion of common non-psychotic mental disorders (CMD) - depression and anxiety - as exposures was based on evidence suggesting an association between CMD and cardiovascular diseases and diabetes. ${ }^{12,17}$ Similar to what happened with food intake, the discussion was about which measure instrument to use. There are short instruments such as the 12-item General Health Questionnaire-12 (GHQ-12) ${ }^{24}$ and the Self-Reporting Questionnaire (SRQ-20) ${ }^{26}$ that can assess whether subjects are non-cases or probable CMD cases, but they do not allow to diagnose the type of disorder. However, the Clinical Interview Schedule-Revised (CIS-R) ${ }^{13}$ follows the International Statistical Classification of Diseases and Related Health Problems-Tenth Revision criteria to classify subjects into six categories of disorders - generalized anxiety disorder, mixed anxiety-depressive disorder, depression, phobias, obsessive-compulsive disorder, and panic disorder - and is less subject to sociocultural bias than the GHQ-12 and the SRQ-20. ${ }^{2,14}$ CIS-R is limited by the fact that it is lengthy and requires good training to minimize systematic or random errors ${ }^{20}$ and to address sensitive situations (e.g., suicidal thoughts). The CIS-R was chosen to be administered in the ELSA because of CMD growing relevance in Brazil and its advantages over other instruments. It was retranslated into Brazilian Portuguese for the ELSA. ${ }^{16}$

Given the ample scope of topics (Table 2) and the questionnaire length - administered in two stages lasting 40 minutes and 2 hours, respectively - topics such as quality of life were excluded. ELSA's longitudinal design will allow to including this and other topics in subsequent waves of data collection.

\section{TRANSLATION AND ADAPTATION OF MEASURING INSTRUMENTS}

Once topics and related instruments were chosen to be included in the ELSA-Brasil questionnaire, we followed standard guidelines ${ }^{11}$ to translate some instruments into Brazilian Portuguese including neighborhood environment rating scales and CIS-R or adapt them (e.g., FFQ) to the cohort population and food intake changes in Brazil over time.

\section{Environment neighborhood rating scales}

There was no Portuguese translation available of the rating scales used in the Project on Human Development in Chicago Neighborhoods (PHDCN)18 and the MultiEthnic Study of Atherosclerosis (MESA).15 These scales evaluate different neighborhood environment dimensions, for example, availability of public spaces for physical activities and access to fresh fruits and vegetables, which have potential impact on cardiovascular diseases. They were selected because of their ease of administration, very good reproducibility of the English version, and potential comparability of results.

The scales were cross-culturally adapted following Herdman et al (1998) recommendations:11 translation of the original English version into Brazilian Portuguese; retranslation (Portuguese version was translated into English by a second translator) with process and result evaluation; probing; and pretesting. Furthermore, a test-retest reliability study was conducted in a subsample of 261 volunteers to evaluate reproducibility of the Portuguese scales. The intraclass correlation coefficients for each scale were: social cohesion 0.83 (95\% confidence interval [95\%CI] $0.78 ; 0.87)$; availability of healthy foods $0.89(95 \% \mathrm{CI}$ $0.86 ; 0.91)$; open space for physical activities 0.90 (95\%CI 0.87;0.92); safety 0.86 (95\%CI 0.82;0.89); and perceived violence: $0.87(95 \% \mathrm{CI} 0.84 ; 0.90) .{ }^{19}$ 


\section{Clinical Interview Schedule-Revised version (CIS-R)}

Many (though not all) sections of the CIS-R had been translated/adapted into Brazilian Portuguese but for use in hospital settings. ${ }^{6}$ We opted for adapting all sections of the original scale version using a standard approach ${ }^{11}$ for the ELSA population, which have a quite different profile from that of inpatients.

The adaptation ${ }^{16}$ comprised steps similar to those described in the adaptation of environment neighborhood rating scales and discussion with experts for final adjustments.

\section{Food Frequency Questionnaire (FFQ)}

The FFQ original version was adapted to the population of Rio de Janeiro ${ }^{20}$ and of five other cities where ELSA study sites are located. A preliminary study was conducted to identify food items to be added to the original list and assess the suitability of household measures (a cup, a ladle) in the light of changes in portion sizes in Brazil over recent decades.

A pilot study of a 24-hour dietary food recall (24HFR) $)^{25}$ was carried out at each study site (total of six 24HFRs) in individuals with age, gender, and education similar to the ELSA population. Based on 24HFR results up to two regional food items or regional marker foods from each ELSA site/city were included (e.g., mate, acarajé [black-eyed pea fritter], cheese bread, São Paulo couscous, Espírito Santo stew). In addition, a set of standard-size tools was used in all ELSA investigation centers (Figure).

\section{THEME BLOCK SEQUENCING}

One of the challenges in developing structured questionnaires is arranging questions so as to make them consistent, facilitate event recall, and minimize losses or refusals. ${ }^{7}$

Questions in the ELSA questionnaire were sequenced taking into consideration that the first half would last 30 to 45 minutes and be administered at the workplace (Stage 1) and the second more extensive half would last 120 to 180 minutes and be administered at the investigation centers along with assessments and measurements (Stage 2).

Stage 1 questions were designed to facilitate empathy between interviewer and respondent and be simple and easy to answer so that respondents would be willing to participate in the study. Given it is a health survey for adults, the opening questions of the questionnaire were about personal and family history of disease. They were intended at the same time to collect data that would allow to defining the profile of losses compared

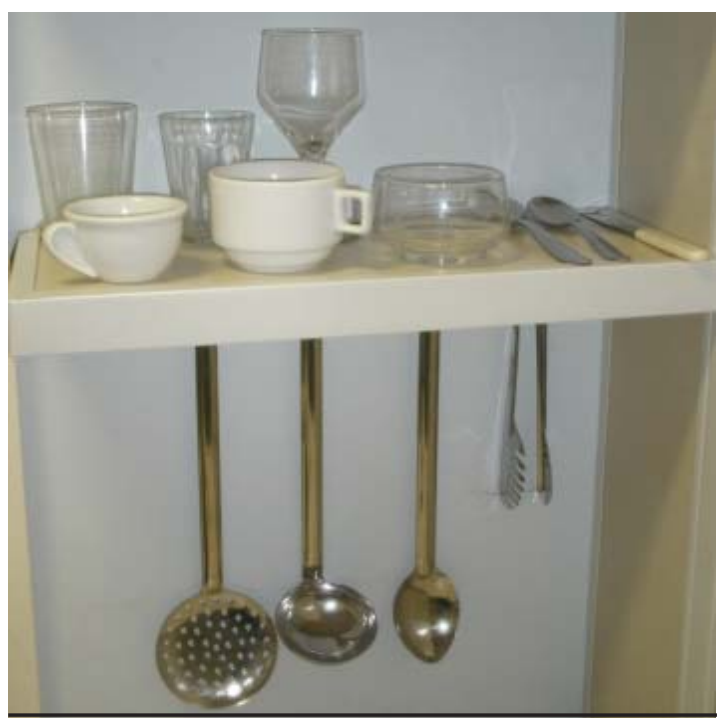

Figure. Standard-size tools for the Food Frequency Questionnaire used in all ELSA-Brasil study sites.

to cohort subjects in case of withdrawal or loss during follow-up. Thus, questions on sociodemographic and family aspects and health-related behaviors and occupational history were also included.

Stage 2 questions asked about specific health problems (e.g., headache and intermittent claudication). These questions were followed by cognitive function testing that required subjects to be rested, and by many other assessments (Table 2). The CMD assessment scale (CIS-R) as well as other scales were applied uninterruptedly after a trusting relationship was established between interviewer and respondent to minimize losses and refusals. The FFQ was administered right after a snack was offered following the second blood collection because it was not advisable to recall food consumption while the subject was fasting or after drinking the solution for glucose tolerance test. The closing questions of the interview were about experiencing social discrimination because it is a sensitive issue.

For constructing the flowchart alternating assessments and questions of the interview, we sought to ensure efficiency by optimizing the utilization of rooms and human resources and the same interviewer whenever possible. But, above all, we tried to provide the most comfortable and less exhausting interaction between respondents and interviewers to ensure quality of data collected.

\section{PRETESTING AND PILOT STUDIES}

Pretesting and pilot studies are designed to reduce the likelihood of measurement errors1 by checking if the questions are clear, the respondent's response to sensitive questions, adequacy of answer choices, 
"skip" of questions required when the respondent do not have to answer certain question, and the sequence of theme blocks. In addition, as ELSA is a multicenter study, specific aspects that characterize the population of each participating city were only identified in these "trials"20 (for example, the inclusion of synonymous food items in the FFQ).

Specific sections of the questionnaire draft were successively pretested at the six ELSA investigation centers. Three rounds of concurrent pretesting were then carried out, totaling 73 interviews with outsourced employees of participating institutions or servers of other public institutions with age, gender and education profiles similar to those of ELSA population.

Questions, comments and praise of volunteers and interviewers on the questionnaire structure, arrangement and administration were reviewed and any changes were incorporated into the different versions of the questionnaire. For example, shift work schedule and which kinship ties should be considered as "family members" in the social capital scale required to be clearly defined.

It also became evident after pretesting that detailed guidelines should be provided in the Interview Guide. Interviewers were trained to give cues in a consistent manner to help the respondent recall information, for example, age at menarche, using the following question: "Do you remember in which school grade you were when you had your period for the first time?". Another helpful guidance was on the intonation of "not" in questions that remained negative in the translation to comply with the original English questionnaire (e.g., "People in your neighborhood generally DO NOT get along with each other.”).

Pretests also suggested that answer cards should be handed to the respondent for rating scales with similar choices in different questions and in those questions for which there was an extensive list of choices, as in CIS-R.

Rounds of questionnaire pretesting were carried out until all problems were identified and corrected. Then a pilot study with a three-stage strategy and a "full-scale rehearsal"9,21 were simultaneously conducted at the six ELSA investigation centers. New assessments and measurements were added at each new stage of the pilot study. A simulation of the real interview including all study procedures in sequence was carried out in a sample of 360 volunteers who had characteristics similar to the pretesting population. All volunteers signed a simplified free informed consent form to comply with ethics concerns in all stages of ELSA preparation.

The first pilot study was conducted in June 2008. It included 12 subjects who were outsourced employees of participating institutions or public servers of other public institutions. There were conducted only actions of stage 1 of the study - recruitment and part I of the interview - at the workplace, which allowed to assess privacy for the interview and estimated duration of this stage.

The second pilot study $(\mathrm{n}=30)$ included the study assessments and measurements and part II of the interview to be conducted during the subject's visit to the study site. The third pilot study was carried out in August 2008 with 107 subjects. All procedures that were part of the study visit were tested. We sought to identify uncomfortable situations, for example, administering the questionnaire while the subject was fasting.

A major goal of the pilot study was to test the interview flow including assessments, sections of the questionnaire, and measurements (pace and duration) as it would certainly have an impact on a subject's willingness to participate, quality of data provided, and participation of his/her colleagues (word of mouth was the strategy used to advertise the study). At this stage, volunteers were actively asked to give their impressions and suggestions. This feedback was recorded and was crucial for improving the flow, alternating interview sections, clinical and biological assessments, and snacks.

The pilot studies also assessed interviewer workload. Short breaks between each section of the interview were allowed and, in Rio de Janeiro, training was provided to improve verbal communication and prevent vocal cord conditions.

Feedback and comments from each stage of the pilot studies were summarized in a report at each study site and forwarded to the EEC and Quality Control Committee. All relevant changes were reviewed and implemented by the ERSC. Pretesting and pilot studies were key for greater internal validity of results through standardization of interviews in the six investigation centers. They also facilitated fieldwork as most issues were addressed and helped build team confidence.

\section{FINAL CONSIDERATIONS}

It is not an easy task to develop a survey questionnaire to collect valid information. Like in many studies, the ELSA had a permanent supervision team to review unsuspected interpretations of questions and answer choices. Learning from experience can be more enriching than learning from books or manuals, and all those involved in the development and quality control of the questionnaire and interviews have learned a great deal. In this article we shared our experience with readers to contribute to the improvement of epidemiological research in Brazil. 


\section{ACKNOWLEDGEMENTS}

We thank the team of interview supervisors for their dedication to ensuring data quality: Esther Paiva Souto, Luciana Ribeiro Abranches, Roberta Carvalho de Figueiredo, Jacqueline Fink, Andrea Pinheiro Poyastro, Tatiane Rosa Ribeiro, Ana Angélica Martins da Trindade, Claudia d'Oliveira Arede and Isabela Ayumi Kesen Araújo.

We thank researchers and fellows for their help developing the questionnaire: Eduardo Faerstein (Instituto de Medicina Social/UERJ), Claudia de Souza Lopes (Instituto de Medicina Social/UERJ), Mariana Miranda Autran Sampaio (Coordenadoria de Auditoria e Desenvolvimento/Tribunal de Contas do Estado do Rio de Janeiro), Danielle Nogueira Ramos (Coordenação Geral de Prevenção e Vigilância/Instituto Nacional de Câncer - INCA/MS), Luís Eduardo Teixeira de Macedo (doctoral student of Instituto de Medicina Social/UERJ), Maria Luiza Garcia (Department of Epidemiology and Biostatistics/Instituto de Saúde da Comunidade/Universidade Federal Fluminense), Flavio Carvalhaes (doctoral student of Instituto de Estudos Sociais e Polóticos/UERJ).

\section{REFERENCES}

1. Aquino EM, Barreto SM, Benseñor IM, Carvalho MS, Chor D, Duncan BB, et al Brazilian Longitudinal Study of Adult Health (ELSA-Brasil): objectives and design. Am J Epidemiol. 2011;175(4):315-24. DOI:10.1093/aje/kwr294

2. Araya R, Wynn R, Lewis G. Comparison of the two self administered psychiatric questionnaires (GHQ-12 and SRQ-20) in primary care in Chile. Soc Psychiatry Psychiatr Epidemiol. 1992;27(4):168-73.

3. Bertolucci PHF, Okamoto IH, Brucki SMD, Siviero MO, Toniolo Neto J, Ramos LR. Applicability of the CERAD neuropsychological battery to Brazilian elderly. Arq Neuropsiquiatr. 2001;59(3A):532-6. DOI:10.1590/S0004-282X2001000400009

4. Bild DE, Bluemke DA, Burke GL, Detrano R, DiezRoux AV, Folsom AR, et al Multi-ethnic study of atherosclerosis: objectives and design. Am J Epidemiol. 2002;156(9):871-81. DOI:10.1093/aje/kwf113

5. Bjorner JB, Olsen J. Questionnaires in epidemiology. In: Olsen J, Saracci R, Trichopoulos D, editors. Teaching epidemiology: a guide for teachers in epidemiology, public health and clinical medicine. 3.ed. New York: Oxford University Press; 2010. p.93-103.

6. Botega NJ, Zomignani MA, Garcia Junior C, Bio MR, Pereira WAB. Morbidade psiquiátrica no hospital geral: utilização da edição revisada da 'Clinical Interview Schedule CIS-R'. Rev ABP-APAL. 1994;16(2):57-62.

7. Bowling A. Research methods in health: investigating health and health services. Maidenhead: Open University Press; 1998.

8. Clarke R, Breeze E, Sherliker P, Shipley M, Youngman $\mathrm{L}$, Fletcher A, et al Design, objectives, and lessons from a pilot 25 year follow up re-survey of survivors in the Whitehall study of London Civil Servants. J Epidemiol Community Health. 1998;52(6):364-9.

9. Faerstein E, Lopes CS, Valente K, Solé Plá MA, Ferreira MB. Pré- testes de um questionário multidimensional autopreenchível: a experiência do Estudo Pró-Saúde UERJ. Physis. 1999;9(2):117-30. DOI:10.1590/S0103-73311999000200007

10. Goldthorpe JH, Llewellyn C, Payne C. Social mobility and class structure in modern Britain. Oxford: Clarendon Press; 1987.

11. Herdman M, Fox-Rushby J, Badia X. A model of equivalence in the cultural adaptation of HRQoL instruments: the universalist approach. Qual Life Res. 1998;7(4):323-35.

12. Jain S, Mills PJ, Von Känel R, Hong $S$, Dimsdale JE. Effects of perceived stress and uplifts on inflammation and coagulability. Psychophysiology. 2007;44(1):154-60. DOI:10.1111/j.1469-8986.2006.00480.x

13. Lewis G, Pelosi AJ, Araya R, Dunn G. Measuring psychiatric disorder in the community: a standardized assessment for use by lay interviewers. Psychol Med. 1992;22(2):465-86.

14. Ludemir AB, Lewis G. Investigating the effect of demographic and socioeconomic variables on misclassification by the SRQ-20 compared with a psychiatric interview. Soc Psychiatry Psychiatr Epidemiol. 2005;40(1):36-41. DOI:10.1007/s00127-005-0840-2

15. Mujahid MS, Diez-Roux AV, Morenoff JD, Raghunathan T. Assessing the measurement properties of neighborhood scales: from psychometrics to ecometrics. Am J Epidemiol. 2007;165(8):858-67. DOI:10.1093/aje/kwm040

16. Nunes MA, Alves MGM, Chor D, Schmidt MI, Duncan BB. Adaptação transcultural do CIS-R (Clinical Interview Schedule- Revised version) para o português no Estudo Longitudinal de Saúde do Adulto (ELSA). Rev HCPA. 2011;31(4):515-8.

17. Rosengren A, Hawken S, Ounpuu S, Sliwa K, Zubaid M, Almahmeed WA, et al Association of psychosocial risk factors with risk of acute myocardial infarction in 11119 cases and 13648 controls from 52 countries (the INTERHEART study): casecontrol study. Lancet. 2004;364(9438):953-62. DOI:10.1016/S0140-6736(04)17019-0

18. Sampson RJ, Raudenbush SW, Earls F. Neighborhoods and violent crime: a multilevel study of collective efficacy. Science. 1997;277(5328):918-24. DOI:10.1126/science.277.5328.918

19. Santos SM, Griep RH, Cardoso LO, Alves MGM, Fonseca MJM, Giatti L, et al. Adaptação transcultural e confiabilidade de medidas de características 
autorreferidas de vizinhança no ELSA-Brasil. Rev Saude Publica. 2013;47(Supl 2):122-30

20. Sichieri R, Everhart J. Validity of a Brazilian food frequency questionnaire against dietary recalls and estimated energy intake. Nutr Res. 1998;18(10):1649-59. DOI:10.1016/S0271-5317(98)00151-1

21. Szklo M, Nieto JF. Epidemiology: beyond the basics. 2.ed. Sudbury (MA): Jones and Bartlett Publishers; 2007.

22. The ARIC investigators. The Atherosclerosis Risk in Communities (ARIC) Study: design and objectives. Am J Epidemiol.1989;129(4):687-702.
23. Van Der Gaag M, Snijders TAB. The Resource Generator: social capital quantification with concrete. Soc Networks. 2005;27(1):1-29. DOI:10.1016/j.socnet.2004.10.001

24. Werneke U, Goldberg DP, Yalcin I, Ustün BT. The stability of the factor structure of the General Health Questionnaire. Psychol Med. 2000;30(4):823-9.

25. Willett WC. Nutritional epidemiology. 2.ed. New York: Oxford University Press; 1998.

26. World Health Organization, Division of Mental Health. A user's guide to Self-Reporting Questionnaire (SRQ). Geneva; 1994.

The Brazilian Longitudinal Study for Adult Health (ELSA-Brasil) was funded by the Brazilian Ministry of Health (Division of Science and Technology [DECIT] of the Department of Science and Technology) and the Brazilian Ministry of Science and Technology (FINEP - Studies and Projects Finance Organization and CNPq - National Council for Scientific and Technology Development, protocol numbers 01060010.00 RS, 01060212.00 BA, 01060300.00 ES, 01060278.00 MG, 0106 0115.00 SP, $01060071.00 \mathrm{RJ})$.

The authors declare that there are no conflicts of interest.

This manuscript was submitted for publication and underwent a peer review process as any other manuscripts submitted to this publication, and anonymity was guaranteed for authors and reviewers. Editors and reviewers declare no conflicts of interest that may affect the peer-review process. 